Mesa redonda

\title{
Convenção dos Direitos das pessoas com deficiências e a lei n.o 10.216
}

\author{
Convenção dos Direitos das Pessoas com Deficiências e o Quality Rights \\ Roberto Tykanori Kinoshita \\ Direitos dos usuários de serviços de saúde mental \\ Jefferson Aparecido Dias \\ CAPS e Quality Rights \\ Fernanda Nicácio
}

\section{SciELO Books / SciELO Livros / SciELO Libros}

KINOSHITA, R.T., DIAS, J.A., and NICÁCIO, F. Convenção dos Direitos das pessoas com deficiências e a lei n.o 10.216. In: BARROS, S., BATISTA, L.E., and SANTOS, J.C., comps. Saúde mental e reabilitação psicossocial: avanços e desafios nos 15 anos da Lei 10.2016 [online]. Uberlândia: Navegando Publicações, 2019, pp. 69-87. ISBN: 978-65-81417-07-9.

https://doi.org/10.7476/9786581417079.0005. Transcrição dos Anais do II Encontro de Saúde Mental - Reabilitação Psicossocial: avanços e desafios 15 anos após a Lei 10.216, Uberlândia, MG, 2016.

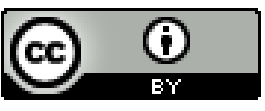

All the contents of this work, except where otherwise noted, is licensed under a Creative Commons Attribution 4.0 International license.

Todo o conteúdo deste trabalho, exceto quando houver ressalva, é publicado sob a licença Creative Commons Atribição 4.0.

Todo el contenido de esta obra, excepto donde se indique lo contrario, está bajo licencia de la licencia $\underline{\text { Creative }}$ Commons Reconocimento 4.0. 


\section{Mesa redonda - Convenção dos Direitos das pessoas com deficiências e a lei $n .^{\circ} 10.216$}

Coordenação: Prof. a Dr. ${ }^{a}$ Márcia Aparecida Ferreira de Oliveira - Enfermeira, Professora Associada do Departamento de Enfermagem Materno-Infantil e Psiquiátrica da Escola de Enfermagem da USP

\section{Convenção dos Direitos das Pessoas com Deficiências e o Quality Rights - Prof. Dr. Roberto Tykanori Kinoshita}

Médico, Psiquiatra, Ex-Coordenador Nacional de Saúde Mental, Álcool e Outras Drogas do Ministério da Saúde do Brasil. Coordenador da Área técnica de Saúde Mental, álcool e outras drogas do Município de São Paulo, Professor adjunto da Universidade Federal de São Paulo - UNIFESP

Bom dia. Eu vou fazer uma introdução ...sobre a questão da convenção. Mas eu queria chamar a atenção para uma questão assim, uma introdução genérica, sobre a questão das leis, e eu estava vendo aqui uma instrução da convenção. Resumo, primeira coisa, a questão de lei natural, próximo (slide). A discussão de lei natural, é curioso porque a gente observa na natureza....

Todo mundo sabe o que é isso aqui? Sequência de Fibonacci. Assim, é uma sequência na qual o número seguinte é a soma dos dois anteriores. Essa é uma coisa que assim na natureza se observa, se identifica isso, essa sequência. São proporções, proporções que são consideradas assim como parâmetro do justo, do correto, do belo, serve para essa noção. E isso você vai observar em diversos fenômenos naturais que seguem essa lógica né. Isso por muito tempo foi uma referência. Aí, está Da Vinci, (slide)...para pensar a natureza e o homem como a justa medida das coisas. Então, esse imaginário de que a natureza, o certo, o correto e o justo, tem uma medida e uma proporção correta está impregnado na nossa cultura.

O que é o justo? O que é o belo? Existe uma proporção correta? Então, não sei se vocês já viram. Bom, justificativas do que é a beleza feminina nesse momento? Raças negras, orientais ou brancas, os padrões em tese são considerados os mesmos, só trocou 
a cor. E essa ideia é tão impregnada que a gente pensa assim "bom, a maior parte dos humanos está fora da lei, a maior parte dos humanos está fora da lei natural". De fato, na verdade, infelizmente, o Da Vinci pensava um ser humano, mas a gente na nossa prática, a gente vê esse ser humano. Esse é mais próximo daquilo que a gente vive no cotidiano. E a questão esse núcleo chama até cultural, emocional, porque é uma emoção quando você diz assim “O Homer Simpson é feio", ele está fora da ordem, está fora da proporção, está fora da norma, está fora daquilo que nós vamos entender como o belo, o justo e o correto, mas a grande maioria dos humanos se identifica mais com Homer Simpson do que com o homem de Da Vinci. Eu queria começar a partir daí porque quando a gente vai falar sobre a convenção, sobre os direitos da pessoa com deficiência, mais para a gente contextualizar. Essa convenção ela foi assinada pelos países membros da ONU no final de dois mil e oito e incorporada no Brasil através de um decreto à constituição brasileira. Essa é uma coisa curiosa, na verdade a nossa constituição de oitenta e oito ela previa que esses documentos internacionais que o Brasil assina deveriam ser todos incorporados na nossa lei, na verdade essa convenção foi a única de fato formalmente incorporada na constituição, integrada à constituição.

Então a convenção dos direitos das pessoas com deficiência tem para todos os efeitos no Brasil efeitos constitucionais, pode-se receber críticas dizendo que nossa constituição nesse momento não está valendo grande coisa, mas de fato a convenção faz parte e essa convenção veio derivada a partir da declaração universal de direitos do homem, então ela tem um fundamento anterior que é a declaração universal de direitos do homem. Antes, o tema deficiência, eu tenho feito muita encrenca por aí, por quê?

A convenção na língua portuguesa tanto no Brasil quanto em Portugal foi traduzida pelo termo deficiência, na língua inglesa, o debate internacional se deu em inglês, o termo é desability, e no campo semântico inglês desability já um neologismo, é uma construção de uma palavra nova, é um consenso de uma palavra nova para denotar um significado novo. E essa é uma das coisas a meu entendimento, por isso que eu arrumo encrenca, na conjuntura nacional dos movimentos sociais, das disputas internas dos movimentos sociais ligados às pessoas com deficiência acordou-se de adotar o termo deficiência, na verdade não é acordou, é manter o termo deficiência no texto assim como uma continuidade dos debates que haviam nesse campo. Isso traz para nós um problema, por que? Para nós, digo nós do campo da saúde mental, traz uma questão: o desability, um dos vetores das necessidades de um termo novo, ao menos se diz 'ametodicamente, que um grupo muito importante na produção desse texto foi um grupo americano dos survivors of psychiatry, sobreviventes da psiquiatria, que é um grupo de militantes or- 
ganizados, americano, que se designam sobreviventes da psiquiatria e participaram do debate da convenção dizendo que eles também querem fazer parte desse processo, da questão da convenção.

Então a deficiência traz confusão, porque tradicionalmente em inglês também deficiência mental é QI baixo, deficiência intelectual, literal, e não correspondia as questões que os sobreviventes da psiquiatria traziam, que são pessoas vindas do campo do transtorno mental, campo de drogas. Então, desability é um termo que surgiu na composição, um guarda-chuva maior que envolve literalmente as pessoas com transtornos mentais e problemas com álcool e droga; no brasil ficou como deficiência, isso traz um grande problema, inclusive político, em Brasília, nós tivemos lá algumas reuniões, algumas convenções públicas, parceiros, companheiros de outros movimentos, levantam e dizem assim "nós entendemos que as pessoas de transtorno mental não deveriam estar aqui", e não estavam mesmo porque não foram convidados.

Nós entendemos que a pessoa que usa drogas não deveria estar aqui, porque a pessoa que usa droga o problema dela é usar drogas, não é deficiente." Então isso traz um debate, trouxe no campo grande confusão, que é movimento das famílias com crianças autistas, porque nessa perspectiva conceitual eles lutaram, conseguiram se organizar para produzir uma lei que afirma que autismo é uma deficiência. Aí, cria-se uma confusão porque esses movimentos das famílias autistas dizem que autismo não é um transtorno mental, que é uma deficiência.

Aí é uma confusão, não é um transtorno mental então não devia ter psiquiatra, não, mas tem que ter psiquiatra. Quem atende? Quem cuida? Mas isso são decorrências digamos assim, muito confusas do campo e trazem operacionalmente para nós debates, debates não só conceituais, envolvem disputas de recursos, disputa de contratação de profissional, disputas inclusive no campo do exercício do direito; não sei se vocês já estiveram, deve ter tido situações, usuários nossos dizem assim "eu não quero, eu não sou deficiente, eu não quero ser acolhido na lei brasileira da inclusão", que é uma outra decorrência.

A Lei brasileira da inclusão está baseada na convenção e ela garante um conjunto de direitos. Ah, "mas eu não sou deficiente eu sou louco", ou o inverso a pessoa diz assim "não, mas eu quero ser reconhecido como deficiente, eu sou louco e deficiente. Eu quero os direitos, eu quero ter acesso, então muda meu diagnóstico." Aqui em São Paulo, especificamente, benefício do transporte de ônibus, chama assim; os requisitos são pensados a partir da convenção da SIF que é um dos pilares também da convenção, a questão do diagnóstico através do código de funcionalidade e não do CID. Os médicos 
não conhecem a SIF, dando diagnósticos, não conseguem permitir acesso aos nossos usuários, direito ao transporte público. Porque o requisito é que você descreva as disfuncionalidades das pessoas através do SIF e não através do CID, não adianta dizer "ah a pessoa tem esquizofrenia", esquizofrenia não quer dizer nada perante a SIF, então não permite acesso a diretos. Bom, o resumo desse tópico aqui é o seguinte: ou o campo da saúde mental que envolve álcool e drogas disputa, se apropria da convenção ou os nossos usuários saíram prejudicados.

Nós precisamos nos apropriar, entrar e fazer valer que a convenção, estou até quase desistindo de brigar para mudar a tradução, mas ainda não desisti disso não, porque a tradução nos prejudica, o conjunto do dobrado das leis civis, o código civil faz muita confusão ainda, o ordenamento legal ainda do que é deficiência é deficiência intelectual, ponto não tem outra, então você tem que chegar no advogado e dizer "não, olha existe a convenção que está na constituição entra com uma petição". Tudo se torna barreiras jurídicas para você conseguir fazer o exercício do direito que está inscrito, este que está editado, não é uma coisa inédita, está editado para publicar.

A convenção, o artigo primeiro traz uma discussão de definição diz assim: "pessoas com deficiência são aquelas que têm impedimentos de longo prazo de natureza física, mental, intelectual ou sensorial, os quais em interação com diversas barreiras podem obstruir sua participação plena e efetiva na sociedade e em igualdade de condições com as demais pessoas", eu acho que esse é o núcleo central de todo o espirito da convenção, detalhe - para alguns comentaristas que fazem a seguinte interpretação correta, diz assim “ essa convenção é um passo adiante em relação ao modelo de pensar as pessoas, a partir de um modelo estritamente biomédico" esse é um fato uma tentativa de superar o modelo biomédico, e vem dizer além do modelo biomédico agregam-se outros fatores das determinações sociais à questão da deficiência de uma pessoa. Isso traz uma ambiguidade digo assim, ao meu ver é uma fragilidade quase epistemológica, porque uma coisa é você tentar definir a situação a partir da somatória de atributos, um atributo biomédico, um atributo social, um atributo disso, um atributo daquilo, esse é um modo de tentar definir coisas, é uma somatória, a questão do indivíduo mais os elementos da sociedade. Eu acho que isso é uma interpretação frágil da ideia de desability no meu entendimento a gente precisa conceber não um somatório de atributos, tipo ele é esquizofrênico, pobre, negro, isso, mais isso, mais isso, mais isso, esse é um jeito de pensar, numa camada social $\mathrm{x}$, de uma categoria yz, quer dizer a gente faz uma somatória de atributos, ao meu ver não se trata disso, porque essa somatória de atributos é problema de aritmética, você soma e ponto final. 
A questão, que eu acho que é importante, é que esta definição ela sai da questão de uma lógica de atributos para se pensar em um objeto relacional, desability ou a tal da deficiência em português, não se trata de uma soma de atributos, mas se trata de uma avaliação de uma relação. Que relação? Primeiro, juridicamente a gente está discutindo uma pessoa, agora a constituição dessa pessoa, o entendimento sobre essa pessoa é uma avaliação de um indivíduo nas suas circunstâncias, na relação com a sua circunstância. A pessoa, ela tem que ser vista na relação, e a desabilidade é o produto dessa interação, indivíduo e circunstancias, numa certa relação, não é uma somatória, mas é uma relação, não é uma questão de soma, mas é uma razão. Por que que isso é importante? Porque isso dá lógicas operacionais distintas, se você pensar a equação $a+b+c$, para você equalizar ou é mais ou é menos, tendencialmente a sociedade faz equalizações tendem a fazer conta de menos, não faz conta de mais, nós entendemos assim, se o sujeito é menos então ele merece menos, porque ele faz menos, contribui menos, faz menos então tem menos.

Nossa tradição de conceito de justiça vem desse tipo de raciocínio, quem tem menos merece menos quem tem mais merece mais. E isso, a nós não nos interessa, acho que a constituição de oitenta e oito ela vem em diversos setores trabalhando a ideia de equidade, equidade não é, literalmente, uma questão de uma soma, mas equidade é uma razão, equidade não é $\mathbf{a}+\mathbf{b}$ ou $\mathbf{a}-\mathbf{b}$ é a sobre $\mathbf{b}$, uma razão. Porque que essa questão da razão é fundamental? Porque é a relação que determina a condição da pessoa. O sujeito em uma certa situação tem um termo, impedimento no seu corpo, agora a atuação deste corpo no mundo depende da suas circunstancias.

Quando eu tinha aula de genética um aluno, um colega levantou e falou assim “ah, mas professor me explica por que que então eugenia não é válida, a gente deveria eliminar pessoas que tem defeitos” então o professor levantou duas questões, primeiro a demonstração aritmética, aritmética não, matemática do quanto a penetrância dos genes tem uma certa diferença e como a capacidade de variação a partir de mutações é muito maior do que nossa capacidade de eliminação, então será um esforço perdido; a parte a isso, falou assim - além disso a humanidade tem alguns momentos históricos que mudam essa relação dos indivíduos no seu meio, por exemplo quantos míopes estão presentes aqui na sala? Vamos ver, levantem a mão os míopes. Aí esse meu professor falou assim "e a humanidade é tão sábia que consegue fazer dos míopes alguma coisa útil, tanto é que nessa sala muita gente é míope". Porque inventa um dispositivo que muda a nossa relação com as nossa circunstancias, ou seja, as nossas circunstancias são transformáveis a partir de um dispositivo relativamente elementar; Espinosa trabalhou muito tempo fazendo lentes para ajudar as pessoas a mudar a sua relação com 
o mundo. Esse aspecto é um aspecto essencial que a gente consiga incorporar, nossa tarefa a partir da convenção é fazer essa avaliação do indivíduo na sua circunstância e como a gente transforma essa circunstância, porque não basta, essa é a grande sacação, os indivíduos não são avaliados em si no éter, são indivíduos em um contexto com uma história, em um lugar, nas suas circunstancias, tem limites porque cada corpo é limitado, nós historicamente temos problema com nossas finitudes não é, é um tema filosófico milenar, nossas limitações, uns tem mais outros tem menos, mas todo mundo tem suas finitudes. Eu entendo que o reconhecimento da finitude, o entendimento da filosofia sobre a finitude é o que nos torna capazes de associarmos uns com os outros, porque ao reconhecer nossos limites e perceber o limite do outro também coopera a gente descobre na nossa história humana que juntos a gente supera nossos limites, que o que temos de mais comum entre cada indivíduo humano é que somos limitados e a superação do reconhecimento, a consciência dessa limitação nos permite compor, agregar, e superar a limitação de cada um, o famoso todos juntos somos fortes, somos mais que um monte de gente, somos mais que uma somatória de pessoas, agregados, reconhecendo o quão quantos somos mais.

Bom é nesse espirito que a convenção se organiza, eu vou saltar eu tenho quantos minutos mais? As outras definições leiam por favor. Existem alguns aspectos que eu destaquei que eu acho que vale a pena, o artigo três tem um item aqui, que diz assim "o respeito pelas dignidades inerentes a autonomia individual, inclusive a liberdade de fazer as próprias escolhas e a independência das pessoas”, depois vem: não discriminação, efetiva participação, mas o aspecto da autonomia individual inclusive a liberdade de fazer s próprias escolhas e a independência das pessoas, aqui na mesma frase agrega-se autonomia e independência, e para mim acho que essa é uma das questões também importantes porque a gente precisa refletir.

Muitos anos atrás tinha escrito essa questão, essa equação de que autonomia não é o oposto da independência, mas é ao contrário existe uma correlação entre autonomia e independência que é o seguinte, autônomo é o sujeito que faz a própria norma, faz a própria lei, essa capacidade de produzir as próprias normas, próprio modo rigorosamente aumenta, quanto maior as correlações e dependências que a gente gera. A autonomia das pessoas, dos indivíduos é maior quanto mais indivíduos ele está agregado e composto, porque nós, voltando a nossa finitude, nos impõe, nós dependemos uns dos outros, a primeira coisa; segundo se o meu grau de dependência é extremamente depositado em poucas relações, em poucos indivíduos, que aí é quantitativo, a dependência é concentrada em poucas relações minha autonomia é restrita, porque a minha capacidade de 
normatizar modos fica mais restrita, se eu tenho muitas relações das quais eu dependo, eu tenho um campo, um domínio de possibilidades, de variação muito maior. Eu acho que essa é uma das questões que a gente precisa raciocinar porque, novamente, como linha de pensamento, linha de trabalho, não adianta você falar assim "ah eu quero autonomia, eu quero independência, eu quero isso, eu quero aquilo" nesse sentido de afirmação de ideias de que pessoas, os indivíduos não necessitam uns dos outros, acho que esse é um grande equívoco, que autonomia ou independência caminha no sentido isolamento, novamente reafirmo aqui a ideia de que na espécie humana nós dependemos mutuamente uns dos outros e quanto mais formos capazes de compor com mais pessoas maior é a nossa autonomia e não o inverso. Acho que essa é uma questão importante. O tema especifico eu destaquei aqui, a questão das mulheres com deficiência, a maior parte aqui provavelmente é mulher. Tomaram todas as medidas apropriadas para assegurar o pleno desenvolvimento, o avanço e o empoderamento das mulheres, afim de garantir o exercício e o gozo dos direitos humanos e as liberdades fundamentais. Não precisa comentar, eu só destaquei porque na lógica, então se é assim não devia nem estar aí, porque somos todos iguais; é exatamente ao contrário, quer dizer se a gente conseguir superar essas situações de extrema desigualdade, de extremo desiquilíbrio, essas distinções são necessárias que sejam explicitadas, reafirmadas, porque se não a gente vai recair que não é necessário fazer mudanças, e é necessário fazer mudanças importantes.

A questão das crianças idem. Criança com deficiência tem direito a pleno exercício de todos os direitos humanos, liberdades fundamentais e igualdade de oportunidade para as demais crianças, direito de expressar livremente sua opinião sobre todos os assuntos que lhe disserem respeito, tenha sua opinião devidamente valorizada de acordo com a sua idade e maturidade. Essa ideia da relação dos adultos com as crianças também acho que é um aspecto que envolve mudanças conceituais, mudanças culturais importantes. Tomando assim um preceito antigo que se dizia o seguinte que quando você tem uma situação de desigualdade, de disparidade, de assimetria de poder, as pessoas que têm menos poder precisam ter mais direitos, essa é uma questão importante, porque as pessoas que têm menos poder têm menos direitos elas ficaram sempre submetidas a uma situação de submissão a quem tem mais poder. Então, a questão da infância está ligada a essa noção, se as crianças têm menos poder elas necessitam de maiores salvaguardas, de mais direitos. Esses direitos a mais precisam ser equalizados na relação. Essa ideia de igualdade não é uma igualdade aritmética, é simples pensar que igualdade é uma relação geométrica, igualdade $\mathbf{a}+\mathbf{b}=\mathbf{c}$ é uma coisa, aritmética, eu estou falando que é uma igualdade geométrica, é que a sobre b é igual a c sobre d, nesse sentido, existe sempre um denominador que modifica e equaliza a relação, isso eu acho que é importante na nossa 
construção cultural. O item doze é superimportante, é um tema polêmico e vou ter que encerrar, mas assim essa convenção ela propõe, ela supõe, coloca como premissa que as pessoas têm plena capacidade jurídica independente do grau de desabilidade.

Como assim? Plena capacidade jurídica independente da capacidade da sua desabilidade. Isso tem consequências para o modo da gente conceber as relações da sociedade, por que? A rigor isso colocaria fora das possibilidades, com algumas extremas exceções, a questão da interdição civil, parte do nosso campo. Porque as pessoas se consideradas plenamente capazes civilmente, e aí o que acontece com o sujeito? Ah o cara tem deficiência intelectual como faz? No debate produziu-se um conceito diferente, que é a ideia de que as pessoas que são plenas da sua capacidade, mas considerando as suas limitações elas precisam de apoio para tomada de decisões. Então a pessoa tem o direito de tomar decisões, de fazer escolhas, expressar a sua vontade, agora cabe ao Estado criar as condições para que essa decisão ela seja informada, contextualizada da melhor maneira, em tese.

Como que a gente vai fazer isso? Esse é um desafio social, cultural, você se na ideia de decisão apoiada, que o sujeito é um sujeito pleno civil e as suas decisões, levando em conta as suas limitações, requer que o estado institua um aparato em torno desse sujeito que lhe permita ser esse sujeito capaz e portanto para ele não sofrer desvantagens, para ele não estar submetido a desvantagem por falta de informação, a falta de capacidade analítica, o conjunto das suas limitações o estado deveria prover um aparato em torno ao qual, baseado no qual ele expressa as suas escolhas e as suas vontades, obvio isso traz questões de conflito de interesse, então esse aparato tem que ser, deveria ser instituído de maneira que não houvesse conflito de interesse, por exemplo herança, por exemplo bens, quem vai herdar e não vai herdar, por exemplo disputas familiares ou disputas pessoais. E acho que este é um dos temas importantes porque nos coloca um desafio como constituir isso, como gerar uma nova cultura, porque se faz uma contraposição de decisão apoiada em substituição, substituir aquilo que se chamava decisão substituta, um tutor, um curador, ele toma decisões substituindo o sujeito que tem limitações, no lugar dele. E a ideia da convenção é não haja alguém no lugar dele, mas que hajam pessoas que suportam esse sujeito na sua condição civil. Hoje colegas, companheiros de São Paulo, nós estamos tirando as últimas pessoas do hospital João de Deus, o município de São Paulo a partir de hoje não tem nenhum hospital psiquiátrico na nossa rede municipal total. Eu queria trazer essa questão aqui, para aproveitar que tem muita gente aqui da rede, eu queria dizer que este é resultado que não tem a ver comigo, eu cheguei tarde nessa gestão, isso também não é produto de um trabalho que se faz em 
poucos meses, na verdade é produto histórico de todos os trabalhadores de saúde mental do estado de São Paulo.

Quero homenagear todos os colegas, companheiros que trabalham aqui, porque no dia a dia eu sei que é muito difícil, tem muitas limitações, tem muitos sofrimentos, agruras do dia a dia, mas é que para um resultado desse talvez quem está lá na ponta, no dia a dia, não se dê conta do quanto essa somatória de esforços criou as condições para que o município de São Paulo não precise de manicômio. Assim, não vou dizer que nós temos uma rede excelente, todo mundo sabe que não está, nem uma rede suficiente, também sabemos que não é, mas esse esforço cotidiano de vocês conseguiu gerar na cidade, condições que não é necessário hospital psiquiátrico, acho que essa é uma demonstração intencional que nós temos hoje e isso é graças ao trabalho de todos vocês, por isso eu agradeço. Parabéns a todos.

Obrigado!

\section{Direitos dos usuários de serviços de saúde mental - Prof. Dr. Jefferson Aparecido Dias}

Procurador da República do Ministério Público Federal, Especialista em Direitos humanos, Membro da Red de Niñez y Adolescencia da Federación Iberoamericana del Ombudsman e da Comissão Permanente da Infância e da Juventude do Grupo Nacional de Direitos Humanos, do Conselho Nacional de Procuradores Gerais, Professor titular da Universidade de Marília - UNIMAR.

Um bom dia a todos e todas. É uma grande honra estar aqui, eu agradeço imensamente o convite. E eu queria falar com vocês sobre a situação do usuário. Eu vou aproveitar um pouquinho o que o Tykanori falou.

É interessante a Convenção, ela é um divisor de águas no que diz respeito à figura da pessoa com transtorno mental. Porque, até então, a legislação brasileira, ela trabalhava com essa pessoa, como quase que fosse uma pessoa não titular de direito. Não de um sujeito de direito. Mas muito mais um objeto direito. Era essa a lógica. Tanto que tinha a curatela como sendo algo para proteger essa visão. Ou seja, negava-se qualquer tipo de capacidade para essa pessoa com transtorno mental. 
A Convenção tenta mudar esse paradigma e reconhece em toda pessoa que tem capacidade em menor ou maior escala. E aí coloca em um plano secundário a lógica da curatela. Essa lógica inaugurada pela Convenção, ela passa a ser - já foi internalizada através de decreto - ela é reafirmada pelo Estatuto da Pessoa com Deficiência. Então, nós deveríamos ter então, a partir daí uma mudança de paradigma. Os juízes, os promotores deveriam atuar em face da pessoa com deficiência, com um outro perfil. Ou seja, fazendo curatelas em momentos única e exclusivamente necessários, no viés patrimonial, que seria essa a nova visão. E incentivando uma lógica de tomada de decisão apoiada. Então, estaríamos às portas do céu mesmo. Os anjos com as suas trombetas, as portas se abrindo e aquela visão maravilhosa do paraíso. Não foi bem isso.

Aqui o primeiro parêntese: é incrível como nós acreditamos nas leis. Porque na verdade, a gente acha que a lei é o fim. Ou o Direito é o fim. E nós não nos damos conta de que na verdade aqui nós estamos falando de bens. Estamos falando só de bens. Bens necessários para uma vida digna. Como que a gente atinge esses bens? Uma das formas de adquirir esses bens é por meio do direito. Então, na verdade o direito à saúde é o caminho pelo qual eu chego aos bens necessários para ter saúde. Mas essa construção mental, nós acabamos nos iludindo de que para acessar esse direito eu preciso de uma lei. E aí existe toda uma lógica legiferante. Então, eu crio uma lei que me garante o direito que permite eu acessar um bem. Não é? É isso. Só que nós nos perdemos nessa lógica e aí a gente começa a lutar só pela lei.

A lei já nos satisfaz. E essa lei, muitas vezes, sequer é posta em prática. Aí nós temos aquela: a lei para inglês ver. A lei que não pegou. E lamentavelmente, me parece que nem a Convenção pegou, lamentavelmente, e nem o Estatuto da Pessoa com Deficiência. Tanto é assim que já existe o PLS 757 de 2015, de proposta do Paulo Paim e Antônio Carlos Valadares, depois tem um substitutivo que é do Mário Mota, que já altera o Estatuto da Pessoa com Deficiência para proteger. Eu acho sensacional esse jogo de palavras. Para proteger a pessoa com deficiência. Para quê? Para proteger ela das escolhas. Porque pela legislação atual só seria o aspecto patrimonial. Mas ela precisa ser protegida no aspecto sexual, ela precisa ser protegida no aspecto pessoal. Ou seja, vamos negar a capacidade mais uma vez. Mas vamos lá: como está funcionando agora? Eu estou com alguns problemas lá em Marília.

Eu sou Procurador Público em Marília e sou Procurador Geral do Estado de São Paulo. Nós temos algumas pessoas com transtorno, que o judiciário exige que ela seja interditada para que ela possa buscar um benefício previdenciário no INSS. Ganhou na justiça. Então tem um saldo para receber. Tem lá 20, 30 mil reais de atrasados. Eu peço 
para o juiz federal remeter para a Vara Estadual, onde tem a interdição para quê? Para que o juiz estadual junto com o promotor estadual junto com o curador, estabeleçam como esse dinheiro vai ser utilizado no projeto de tratamento dessa pessoa com doença mental. Eu acho que é isso. Se esse dinheiro é da pessoa com doença mental, ele deve ser usado em prol dessa pessoa. $\mathrm{O}$ juiz estadual me devolve o processo falando o seguinte, olha: 'não, aqui eu não tenho mais nada. Aqui era só interdição. Eu já interditei, nomeei curador. Mandei para o arquivo o processo. Eu não preciso mais deliberar com relação à prestação de contas. Eu não preciso mais deliberar com relação ao tratamento. Não preciso mais deliberar com relação à curatela'. Só que a lei não dizisso.

A lei diz que o processo deveria continuar vivo. Para quê? Para que o curador prestasse contas do seu encargo. Para que pudéssemos monitorar essa pessoa com deficiência, essa pessoa com transtorno mental, para ver se ela já pode ter levantada a curatela. $\mathrm{Eu}$ ainda estou procurando um processo de levantamento de curatela. Porque eu vejo processos de curatela. E um número cada vez maior de curatelas. Nós estamos criando um exército de zumbis. Tem uma série que está na moda agora, que é The Walking Dead. Nós estamos criando zumbis. Mortos vivos civis. Não é? Eu me lembro de um evento que nós estávamos lá em Curitiba, eu falando sobre curatela. Um jovem lá no fundo levantou a mão e falou:' olha eu queria dar um conselho para vocês: nunca aceitem ser curatelados. Interditados. Curatelados'. Aí eu perguntei: por quê? Ele falou: 'não. O meu pai me convenceu que o bom seria que eu fosse para Universidade curatelado, só que hoje eu não consigo fazer nada, porque ele é o curador e decide tudo na minha vida, então não aceitem ser, eu acreditei que ia ser melhor para mim, mais não foi.' Veja a situação que nós estamos. Então, há na verdade, uma distorção e essa distorção, que pode ser pequena, tem gerado um exército de zumbis civis e, o pior, abusos. Não sei se todos conhecem um que sucedeu, está sucedendo em Sorocaba, é uma luta diária . Agora, todo mundo pode estar acompanhando, mas nós nos declaramos com a situação do que? Uma mesma pessoa, era curadora de duzentas pessoas. Uma! E onde é sensacional? Eram umas oitenta, mais ou menos. Uma vez por mês, ela ia lá pegava as pessoas. Levava para o comércio. Deixava comprar, fazer compras de apenas três horas. Pegava a nota fiscal? Não pegava nota fiscal, ou pegava a nota fiscal em branco. Decidia tudo na vida dessas pessoas, que só iam em algumas lojas, lojas que já tinham uma pré combinação. O pior de tudo, essa pessoa foi liberada, pelo judiciário, foi no Ministério Público, prestar contas, por causa de confiança, não precisava prestar contas. Recebia oitenta salários livres por mês, que não precisava prestar contas, o outro que ganhava duzentos foi até lá e disse: não, mais eu levo ele pra pescar, uma vez por mês, lá no pesque e pague. Esse era otratamento. 
Então veja, são abusos, abusos e abusos, que ocorrem sob as barbas das instituições, com o descumprimento da lei e sem que nada seja feito, quando surge um raio de luz, que seja o estatuto, ele é atropelado, pela prática diária, ele é atropelado pela postura conservadora, ou digamos, uma prática, que não busca qualquer forma, uma pratica emancipadora, uma pratica reguladora, que tenta manter os Estados pobres, teve uma que apresentou com tanta força que se propõe até mesmo a operação da lei, mas se voltar pra trás, né e aí o lamentável de tudo isso é que não vejo que estejamos fazendo algo diferente, lamentavelmente. Comecei a falar, entrei nessa área, há, há, Sorocaba foi quantos anos já, seis anos?. Dois mil e doze? Há quatro anos, os problemas que nós enfrentamos e voltamos a enfrentar são sempre os mesmos, de quatro anos atrás, as vezes eu leio algumas obras de um passado mais longínquo e eu vejo que os problemas ainda são os mesmos. Então, falar em tomar atenção apoiada parece algo ficcional, lamentavelmente, porque não é isso que nós vemos no dia-a-dia. Ainda, nos processos de interdição, os processos de curatela. Acho que vamos ter que mudar o paradigma, se nós não mudarmos as práticas sociais, pouco importa ter a convenção, pouco importa o que o estado está tendo de deficiência, pouco importa processos curativos. Então, tem que forçar para mudar a lógica, para que a pessoa com deficiência, com problemas mental, seja realmente recebida, que realmente nós a reconheçamos como uma pessoa titular de direito. Porque senão, continuarão a ser tratadas como objeto de direito, como algo que deve ser protegido, como se a curatela fosse uma forma eficaz de proteger a pessoa e não me parece. Você protege a pessoa quando você capacita, quando você a emancipa, quando você reconhece nela o diversos direitos, aí as curatelas tem que ser parciais, temporárias, excepcionais. Elas se tornam totais, permanentes, em regra.

Que regra? E o mais estranho é que isso está tão de forma naturalizado. Está de tal forma, que mesmo pessoas que deveriam tutelar um limite de pessoas, lutar pelos Direitos Humanos, quando se dão conta, tão trabalhando a favor dessa lógica reguladora. Eu tenho feito palestras em grupos com Defensoria Pública ou mesmo no Ministério Público, gente houve alguma interdição de curatela? Beleza, agora quem entrou com uma desinterdição, um levantamento de curatela? Ninguém levanta a mão, tá! Então veja, se a outra trabalhando com eventual exército de curatelados, interditados, eu tô colaborando com sistema, que reduz o ser humano ainda a um zumbi civil, um morto vivo civil. Então, o exército de 'The walkig Dead', que vem crescendo de forma assustadora, lamentavelmente. Somos só isso gente? Ainda acho que há, ajustamentos fiscais, capacitação de todos os setores, para fazer novas pericias, novos modos de fazer perícia, novas lógicas. Não é possível, que ainda se faça uma visitação, eu pergunto pra alguém que faz: a pessoa está apto pra usar atos da vida civil? Veja o que são atos da vida civil, então isso 
tem que mudar, não pode, se quer ser perguntado para um perito, . O perito não deveria aceitar a responder isso, ele fala: "olha, depende, atos da vida civil são esses, feliz na lei, então para esses sim, para esses não. Algo mais esmiuçado, temporário, daqui um ano, de seis em seis meses vão reavaliar, vamos levantar a curatela, vamos "desinfectar", isso é um segundo ponto.

E eu nem vou falar com as pessoas com problemas mentais, por incrível que pareça. Tem um quesito que eles colocam a pessoa: Existe alguma possibilidade dessa pessoa voltar a vir, em algum momento no futuro? É sensacional! Eu não sei se eu respondo. Se perguntar, você garante que nos próximos anos, de toda a sua vida até a morte, você nunca vai delinquir, dá? Não dá. Só que não embasa a resposta. O cliente fala corretamente: "não tenho condições de afirmar isso". O juiz fala: fica presa então! Porque ele pode voltar a reviver, na verdade, como anda o mundo acho difícil alguém não delinquir. Em alguns momentos, com a lei posta, eu acho que eu preciso ser classificado como delinquente. Um delinquente que acredita que a lei não é tudo. Um delinquente que precisamos passar a limpo uma lei. Se essa lei é restritiva. Se essa lei é, ela sim, uma violadora dos direitos humanos, porque aí é melhor agir contra lei, isso sim! Mas olha, no nosso caso não precisa nem ir contra a lei. Basta que a lei fosse cumpridas, bastaria que a nossa constituição, lamentavelmente, que tem sido atacada de forma brutal nos últimos tempos, que a convenção e que a lei do próprio Estatuto da Pessoa com Deficiência fossem cumpridos. O que que é isso? Vão perguntar, mais faz parte do jogo. Obrigado.

\section{CAPS e Quality Rights - Fernanda Nicácio}

Terapeuta Ocupacional, Professora do Departamento de Fonoaudiologia, Fisioterapia, e Terapia Ocupacional - FMUSP. Ex-Coordenadora Adjunta da Coordenação de Saúde Mental do Ministério da Saúde do Brasil.

Gostaria de cumprimentar a feliz oportunidade deste Encontro, destacando a riqueza de juntos pensar, de refletir coletivamente, de fazer em conjunto, de projetar, de conviver, em particular em "tempos tão difíceis"...

A realização deste Encontro é muito significativa neste momento, e estão presentes tantas e tantos companheiros desses anos, tantos jovens e também nossos mestres, Saraceno e Giovanna. 
Vivemos “tempos muito difíceis”..., não têm sido raras as ocasiões que sentimos uma certa perplexidade com o que está acontecendo nas terras brasileiras, e são muitas as indagações: Para onde vamos? Como vamos? Como vamos resistir? Resistir no sentido de agir em defesa da liberdade, da democracia, e resistir fortemente à restrição dos direitos conquistados.

Muitas análises têm sido desenvolvidas, tentativas de entender esses "tempos tão difíceis" e destaco uma dessas dimensões, isto é, a perspectiva de futuro que parece, neste momento, nublada, nossa projetualidade está turva... E nesses momentos de perspectivas nubladas, talvez, mais uma vez encontremos, mesmo que ainda distantes, a proximidade com as trajetórias institucionalizadas de vida e, talvez, exatamente por isso possamos, como ensinou Franco Basaglia, aprender com a "força dos loucos".

Para iniciar a reflexão, retomo sínteses das práticas desenvolvidas nesses anos: nos defrontamos com a força da resistência ao abrir as instituições; ao abrir as primeiras enfermarias, descobrimos o quanto os muros manicomiais concretizam saberes e poderes; ao "estar-com" os usuários, identificamos o quanto os territórios precisam ser desbravados; ao ensinar, dialogamos com a presença do senso comum em relação a qual lugar os loucos ocupam na nossa organização social.

Mas, também, nessas práticas, nas enfermarias, nos hospitais psiquiátricos, desde os anos 1980, percebemos a força das pessoas internadas, como estavam ocultos os projetos, as possibilidades das pessoas...; no cotidiano dos primeiros serviços 24 hs descobrimos a riqueza da potencialidade desse recurso; nos processos de ensino, reafirmamos a relevância dos percursos formativos de graduação, e o feliz encontro hoje, inclusive, neste evento, com tantos ex-alunos.

Nos percursos realizados, com tantas pessoas aqui presentes, pudemos encontrar, também, tantos movimentos com a mesma perspectiva ética, e destaco, em particular, o movimento da economia solidária e os diálogos com instituições que, em determinados momentos, pareciam tão complexas. Possibilidades de diálogos, uma vez que nossa bússola sintoniza com movimentos sociais e processos institucionais que buscam "construir um mundo melhor". Assim, na complexidade do momento que vivemos, são muitos os itinerários, e compartilho do que foi salientado ontem por tantos companheiros, da necessária luta em defesa da reforma psiquiátrica, do SUS e do Estado Democrático de Direito.

Por outro lado, em momentos como esse, a nossa utopia "Por uma sociedade sem manicômios" expressa, de forma ainda mais evidente, nosso compromisso ético, 
técnico, e político, com a liberdade, com os direitos, e com a democracia. Revisitando nossa história enfatizo, para a discussão de hoje, alguns momentos que expressam a força da defesa dos direitos e da liberdade no processo de reforma psiquiátrica brasileira. $\mathrm{Na}$ emblemática II Conferência Nacional de Saúde Mental, foi afirmada, de forma enfática, a diretriz de direitos de cidadania (Nicacio, 2003). O debate sobre a insígnia louco-cidadão foi particularmente aprofundado nos anos 1990, e me parece um momento fundamental para esse debate ser revisitado.

Em relação à discussão da liberdade, retomo algumas insígnias que atravessaram o processo da reforma psiquiátrica, citadas em trabalho anterior (Nicacio, Campos, 2007): III Conferência Nacional de Saúde Mental: "Liberdade é o melhor cuidado"; Congresso Brasileiro de CAPS em 2004: "Saúde mental: cuidar em liberdade e promover a cidadania"; Fórum Mineiro de Saúde Mental: "Liberdade, ainda que Tam- Tam”; Tykanori, final dos anos 1980, início da experiência de Santos: "Saúde mental: poder, afeto, e liberdade". Essas insígnias, produzidas na trajetória da reforma, expressam a nova ética que orientou os processos, a formulação de políticas públicas e o desenvolvimento de práticas; mas essa perspectiva não é simples: "cuidar em liberdade" se refere à transformação das instituições asilares, e, também, ao cotidiano dos serviços substitutivos, e produz quais significados no dia a dia dos serviços? (Nicacio, Campos, 2007).

Destaco a defesa de direitos e da liberdade na trajetória da reforma para, nesse momento, pensar o tema específico nesta mesa, CAPS e QualityRights, compreendendo os CAPS como lugares estratégicos para a superação do modelo asilar, e, assim, assume centralidade, a "produção de percursos que promovam, sustentem e viabilizem a afirmação da liberdade" (Nicacio, Campos, 2007), e, também, a promoção de "acesso e exercício de direitos" (Rotelli, 1999).

Convite para pensar essa questão em articulação e diálogo com a Lei 10.216/2001, tema deste Encontro. $\mathrm{O}$ Artigo $2^{\circ}$ apresenta, como salientado, um conjunto de direitos, e "ser tratada, preferencialmente, em serviços comunitários de saúde mental" como um direito; o Artigo $5^{\circ}$ aponta, claramente, a perspectiva da desinstitucionalização e da reabilitação psicossocial.

A partir desta breve síntese, as reflexões que apresentarei se inscrevem no processo de elaboração conjunta de um projeto de pesquisa, em boa companhia de pesquisadores, que cumprimento na pessoa de Sônia Barros, e, também, remetem às discussões que iniciamos quando estávamos no trabalho da Coordenação Nacional de Saúde Mental com a equipe coordenada por Tykanori, sobre o QualityRights. 
Em 2012, a Organização Mundial da Saúde lançou o projeto"WHO QualityRights" na perspectiva de, conforme indica documento da OMS (WHO, s/d), "unir e empoderar pessoas para melhorar a qualidade do cuidado e promover direitos humanos em serviços de saúde mental e de assistência social", e considerou para elaboração desse projeto, a necessidade de "um novo paradigma [...] serviços promotores de recovery que enfatizem [...] autonomia e participação dos usuários em todos os aspectos do tratamento e de suas vidas". O QualityRights tool kit tem como base a United Nations Convention on the Rights of Persons with Disabilities, no cenário nacional Convenção (2011) apresentada neste Encontro em várias discussões. Tendo com referência Artigos da Convenção, o QualityRights tool kit aborda cinco temas (Brasil, 2015):

1. "O direito a um padrão de vida e proteção social adequado", referente ao Artigo 28;

2. "O direito a usufruir o padrão mais elevado possível de saúde física e mental", referente ao Artigo 25 da Convenção;

3. "O direito a exercer capacidade legal e o direito à liberdade pessoal è̀ segurança da pessoa", referente aos Artigos 12 e 14;

4. "Prevenção contra tortura ou tratamentos ou penas cruéis, desumanos ou degradantes, e contra a exploração, violência e abuso", referente aos Artigos 15 e 16;

5. "O direito de viver de forma independente e de ser incluído na comunidade", referente ao Artigo 19 daConvenção.

No QualityRights, para cada um desses cinco temas, estão previstos padrões e critérios para avaliação. A Coordenação Geral de Saúde Mental, Álcool e outras Drogas do Ministério da Saúde apresentou, no site (Saúde Mental), a publicação da tradução oficial para português do QualityRights, e adotou, para o cenário nacional, a denominação: "Direito é Qualidade". De acordo com a referida apresentação: “O componente inovador consiste na perspectiva de promoção da qualidade em serviços de saúde mental enquanto garantia de direitos de seus usuários”. Enfatizo a relevância dessa inovação em termos de avaliação de serviços: a perspectiva de qualidade compreendida como direitos dos usuários, garantia e promoção de direitos. Naquela oportunidade foi disponibilizado o conjunto de cinco ferramentas do QualityRights tool kit (Brasil, 2015): o documento geral de apresentação do conjunto do instrumento; a Ferramenta para Entrevistas; a de Análise de Documentação e Observação; o Relatório de Avaliação nacional; e o Relatório de Avaliação com base no serviço. 
Certamente são muitas as questões a serem discutidas, mas neste momento gostaria de trazer algumas contribuições para pensar em conjunto a proposição do QualityRights e os CAPS. Nessa perspectiva, retomo as questões assinaladas anteriormente - "afirmação de direitos, promoção de direitos" e "cuidado em liberdade" que configuram bases e diretrizes da reforma psiquiátrica, presentes na prática cotidiana dos serviços, assim como na formulação de políticas públicas - e, nesse sentido, considero que a possibilidade de diálogo CAPS e QualityRights pode gerar um potente encontro. Claro que potente encontro a depender do processo que será desenvolvido em relação ao QualityRights que pode produzir uma provocação, provocação aqui no sentido de instigar a reflexão conjunta sobre violação e restrição de direitos, e, também, sobre as experiências de "acesso e exercício de direitos", e com essa perspectiva cultivar, coletivamente, o CAPS como lugar de promoção dedireitos.

Assinalo, então, três questões para pensar junto. Primeira questão: como abordado anteriormente, a Convenção tem sido pouco apropriada no nosso campo; por outro lado, se retomarmos o propósito da Convenção (2011), conforme Artigo $1^{\circ}$, de "promover, proteger, e assegurar o exercício pleno e equitativo de todos os direitos humanos e liberdades fundamentais por todas as pessoas com deficiência e promover o respeito pela sua dignidade inerente", e a análise da trajetória da reforma verifica-se que a premissa da Convenção é presente no processo de reforma. Assim, a Convenção constitui e, em particular nesse momento, pode ser um instrumento bastante importante; nesse sentido, como salientado, é muito importante que o nosso campo possa se apropriar da Convenção.

A segunda questão refere-se ao tema, relativos aos Artigos 12 e 14 da Convenção, "o direito a exercer capacidade legal e o direito à liberdade pessoal", assinalados anteriormente neste Encontro. O cotidiano nos serviços, não só nos hospitais psiquiátricos, mas também nos CAPS, é a presença de pessoas interditadas; cabe ressaltar, também, a complexidade, no dia a dia dos serviços substitutivos, de trabalhar, de operar na prática cotidiana compreendendo as pessoas como "sujeito de direitos". E exatamente por essa complexidade é importante aprofundar a reflexão, uma vez que, de certa forma operam, no cotidiano, muitas armadilhas ao considerar que as pessoas não são capazes, que as pessoas não são capazes para o diálogo, para efetivamente participar. Se, por um lado, a discussão sobre violação de direitos é muito mais evidente, por outro, como operar cotidianamente, e considerando os CAPS para reflexão, com as pessoas compreendidas como "sujeito de direitos" é muito maiscomplexo.

Em relação à relevância da proposição de "capacidade legal", como apontado anteriormente, poderíamos pensar em começar a produzir práticas de “Tomada de Decisão 
Apoiada" (Brasil, 2015); nesse sentido inclusive, recordo do trabalho anterior em Sorocaba, de discussão de como produzir práticas concretas de “Tomada de Decisão Apoiada”, como iniciar práticas concretas nos CAPS, de buscar levantamento de interdição, construindo diálogos com o conjunto de instituições. E, também, como compreender "Tomada de Decisão Apoiada”, sintética e valiosa expressão, no cotidiano das práticas terapêuticas, isto é, quais são os desafios das práticas cotidianas nos CAPS para que seja possível, no campo do cuidado, operar, efetivamente, com essa perspectiva de constituir as equipes, os CAPS, os recursos, como apoio para propiciar, às pessoas com experiência de sofrimento psíquico, novas possibilidades para seus projetos de vida.

Considero que esse tema do QualityRights, com padrões e critérios, pode contribuir como uma estratégia nesse processo de olhar nossas práticas, de pensar em conjunto, de encontrar estratégias, de pensar práticas concretas, porque é claro que se trata, como assinalado, de uma profunda mudança cultural, jurídica, técnica.

A terceira questão para essa reflexão, é o tema do QualityRights relativo ao Artigo 19 da Convenção, que se refere ao "Direito de viver de forma independente e de ser incluído na comunidade". Tema muito claro em todo o processo de reforma, da garantia desses direitos; mas, também, é importante refletir no cotidiano das práticas como tem sido o desenvolvimento de processos que operam no sentido da articulação do apoio efetivo para garantir os direitos ao trabalho, à moradia, e à participação social.

Por essa razão, mais uma vez, penso que o QualityRights pode ser uma estratégia de reflexão sobre como têm sido as práticas de restituir, de promover, de articular "o acesso e o exercício de direitos" (Rotelli, 1999). Em outras palavras, refletir sobre como os CAPS têm operado esse desafio complexo, e tendo como referência as contribuições de Saraceno (1999) e Rotelli (1999) para pensar os processos de reabilitação, citando Rotelli (1999) "construir (reconstruir) acesso real aos direitos de cidadania, o exercício progressivo dos mesmos, a possibilidade de ter reconhecidos esses direitos e de agir, a capacidade de praticá-los".

Para finalizar: os cinco temas, padrões e os critérios do QualityRights certamente abrem um conjunto de reflexões que podem contribuir, podem gerar um potente encontro, QualityRights e CAPS, para a reflexão da prática e a afirmação dos CAPS como "lugares de promoção de direitos".

Claro que ao referir os CAPS, as práticas cotidianas de liberdade e direitos, estamos, evidentemente, discutindo instituições e poder, restituir poder, ampliar poder, fortalecer poder (Saraceno, 1999; Rotelli, 2016). Temos uma extensa literatura sobre o 
lugar do manicômio nas relações sociais, e parece fundamental aprofundar a reflexão sobre o lugar dos CAPS nas relações sociais - e considerando a promoção de liberdade e de direitos, e a restituição e o fortalecimento de poder das pessoas que vivenciam a experiência de sofrimento psíquico, poderíamos refletir sobre a perspectiva dos CAPS, na singularidade do desafio de sua responsabilidade e de seu lugar social, como uma das instituições que compõe a democracia cotidiana e os percursos de ampliação de direitos a partir do cotidiano.

Nesse sentido, um convite para o próximo Encontro com o tema dos CAPS como um dos lugares fundamentais na produção da democracia do cotidiano; próximo Encontro, considerando, de acordo com nosso grande poeta: "Amanhã há de ser outro dia". 